\title{
Un Análisis sobre la Interpretación de los Diferentes Actores en torno a la Educación Intercultural y Bilingüe y sus Políticas
}

\author{
Romina Peschiera Ruju \\ Pontificia Universidad Católica del Perú (PUCP) \\ Instituto de Estudios Peruanos (IEP)
}

Romina Peschiera Ruju es Licenciada en Educación Secundaria (Historia y Geografía) y Magister en Políticas Educativas (Pontificia Universidad Católica del Perú). Autora de artículos relacionados con la Educación Intercultural en el marco de las culturas amazónicas. Además, ha producido material diverso de uso pedagógico, incluyendo textos escolares, tanto para estudiantes como para docentes. Cuenta con amplia experiencia en gestión de proyectos educativos y de investigación.

Agradezco el apoyo del Centro Amazónico de Antropología y Aplicación Práctica (CAAAP), el asesoramiento de Virginia Zavala (PUCP) y el soporte de mi familia y amigos. 


\title{
Un Análisis sobre la Interpretación de los Diferentes Actores en torno a la Educación Intercultural y Bilingüe y sus Políticas
}

\begin{abstract}
Resumen
Las políticas de Educación Intercultural Bilingüe (EIB) en el Perú suelen implementarse sin tener el éxito esperado. Esta investigación se basa en la idea de que una política de EIB no puede tener el éxito esperado si los documentos de política y actores educativos que intervienen en su implementación tienen diversas interpretaciones de la EIB y una percepción poco crítica de la situación sociocultural en el Perú. Esto porque si no existe un consenso en torno a lo que se va a entender por interculturalidad y no se estudian las causas de la problemática sociocultural, las políticas interculturales se podrían tornar idealistas y vacías de significado. De ahí que mediante la realización de entrevistas a profundidad y de un análisis documental, esta investigación busca conocer cuál es la interpretación y percepción de los actores educativos (funcionarios públicos y docentes) en relación a la educación intercultural y bilingüe, y sus políticas.

Si bien los actores educativos entrevistados tienen diferentes formas de interpretar la educación intercultural y un manejo distinto de las políticas, el principal problema encontrado radica en que tanto los discursos que se enuncian en los documentos de políticas, como las interpretaciones que se encuentran en el imaginario de los actores, se basan en una visión acrítica de la realidad sin un punto de partida que oriente qué se entiende por interculturalidad en la educación, lo que conlleva a que predomine una mirada idealista y descontextualizada de la interculturalidad, invisibilizando las relaciones de poder y conflicto existentes en la sociedad, perpetuando la desigualdad a favor de la cultura dominante. Es a partir de estos resultados que se brindan algunas orientaciones para esclarecer el debate que se encuentra presente en la formulación e implementación de las políticas educativas interculturales y bilingües.
\end{abstract}

Palabras clave: política educacional, educación intercultural, educación bilingüe 


\title{
Analysis of the Interpretation of Different Actors about Intercultural and Bilingual Education and its Policies
}

\begin{abstract}
Intercultural and Bilingual Education (IBE) policies in Peru are usually implemented without reaching the expected results. Among the causes that originate this situation, this investigation is based on the idea that an IBE policy cannot be successful if the educational actors that participate in its implementation have different interpretations of this matter and no critical perception of the social and cultural situation in Peru. This is because if there is no agreement between what is going to be interpreted as interculturality and if the causes of the social and cultural problems are not studied, then the intercultural policies turn idealistic and empty of significance.

Through in-depth interviews to different educational actors and analyzing political documents, this investigation searches about the perception and understanding of educational actors (public authorities and teachers) about intercultural and bilingual education and its policies.

Even though the educational actors interviewed have different ways of interpreting intercultural education, and a diverse management of IBE policies, the main problem found lies in the fact that the speeches enunciated in the policy documents, and the interpretations of intercultural and bilingual education that were found in the actors, are based on an uncritical vision of reality without a common interpretation that leads what is going to be understood of interculturality in education. The consequence is the predomination of an ideal and non real interpretation of interculturalism, hiding the links between cultural relations and existing conflicts in society and perpetuating the inequality in favor of the hegemonic culture. It is from these results that some orientations are presented to clarify the discussion about the formulation and implementation of intercultural and bilingual educational policies.
\end{abstract}

Keywords: educational policy, intercultural education, bilingual education 


\section{Introducción}

Cegún diversas experiencias y estudios (Tapnell \& Neira, 2004; Zúñiga \& Ansión, 1997; Zúñiga \& Gálvez, 2005), muchas de las políticas de Educación Intercultural Bilingüe (EIB) plantean metas que no llegan a cumplirse en su totalidad. Esta investigación parte del supuesto que una política de educación intercultural y bilingüe no se puede aplicar exitosamente si no hay un consenso entre los principales actores de lo que ésta significa y si existe una percepción poco crítica de la situación sociocultural en el Perú. Esto porque sin un consenso en torno a la interpretación de la EIB y si no se estudian las causas de la problemática sociocultural, las políticas interculturales podrían tornarse idealistas y vacías de significado ${ }^{1}$.

Por ello esta investigación busca responder a la pregunta: ¿cómo la educación intercultural y bilingüe, y sus políticas, están siendo asumidas e interpretadas en el imaginario de los actores de los diferentes niveles del sistema educativo?

El principal aporte del estudio radica en que es un punto de partida para conocer, a partir de la interpretación de los actores educativos y de los documentos de política, qué tanto consenso existe en torno a la EIB y cómo es la percepción al respecto (¿crítica o no crítica?), para contribuir a la generación de acuerdos que le den mayor legitimidad social a la EIB y sus políticas.

Sus objetivos son:

- Identificar y analizar el contenido y coherencia interna de las políticas y normativa oficial de la EIB existentes dentro de Ministerio de Educación (MED).

- Identificar la concepción de interculturalidad y EIB que manejan los diversos actores educativos, así como el conocimiento e interpretación que tienen sobre las políticas de EIB.

- Analizar y reflexionar sobre las formas que tienen los actores educativos de asumir e interpretar la EIB y sus políticas.

- Esclarecer y orientar el debate que se encuentra presente en la formulación e implementación de las políticas educativas interculturales y bilingües.

1 Con un consenso en torno al entendimiento de la interculturalidad en la educación no se pretende que una EIB se aplique a todos por igual, ya que claramente ésta debe aplicarse de forma diferenciada según las distintas realidades (Tubino, 2004). 
Para cumplir con estos objetivos, el recojo de información se realizó a través de un análisis documental, para lo que se revisaron y analizaron trece documentos normativos de políticas nacionales y educativas.

Asimismo se realizaron entrevistas en profundidad a los actores que intervienen en los diferentes niveles del sistema educativo en la costa y selva del Perú. Se escogió entrevistar a funcionarios de estas dos zonas con el fin de identificar y contrastar su interpretación de las políticas, asumiendo que cada zona presenta diferencias culturales que podrían estar afectando esta interpretación. En total se entrevistó a 21 actores educativos entre funcionarios del MED, Direcciones Regionales de Educación (DRE), Unidades de Gestión Educativa Local (UGEL) y docentes ${ }^{2}$.

\section{Concepciones de Cultura e Interculturalidad}

Para comprender la interculturalidad, es necesario partir del concepto de cultura, ya que de esto dependerá lo que cada grupo interprete. Al respecto, Castro-Gómez (2000) se refiere a una teoría de las culturas tradicional y una crítica. La teoría tradicional se caracteriza por una actitud pasiva y relativista, frente a la teoría crítica, la cual considera que la ciencia y la realidad estudiada por ésta son producto de una praxis social. En este sentido, sujeto y objeto son afectados por la misma presencia del otro. De ahí que hay una profunda y contradictoria interrelación dialéctica entre sujeto y objeto. Entonces, si en el encuentro cultural se es consciente de que uno mismo es sujeto, con sus propios intereses, ideas y prácticas culturales, y a su vez es objeto para el otro, se podrá dialogar en mejores condiciones con los demás, pues se podrá comprender por qué se dan las relaciones de poder entre culturas y pensar cómo mejorar la realidad.

Desde esta mirada, es necesario reflexionar desde la teoría crítica cómo se dan las relaciones culturales. Según Fuller (2005), la mundialización, donde occidente ocupa un lugar central, ha significado un cambio en las culturas

2 Se entrevistó a 6 funcionarios del MED (inicial, primaria, secundaria, superior y 2 de la Dirección de Educación Intercultural Bilingüe - DEIB), 8 especialistas de las DRE y UGEL (Tumbes, Madre de Dios, Chanchamayo, 3 de San Martín y 2 de la provincia de Islay -costa arequipeña) y a 7 docentes ( 3 docentes de la costa de niveles inicial y primaria y 4 docentes de la selva de nivel primaria EIB, principalmente docentes asháninka del Río Tambo -selva central del Perú). 
debido al aumento de las relaciones de transculturación ${ }^{3}$ entre éstas. Estos encuentros generaron grandes cambios difíciles de percibir para el pensamiento occidental, sumamente etnocéntrico. Esta transculturación a favor de la cultura dominante tiene como base un imaginario social heredado del periodo colonial, que justificaba y garantizaba el orden jerárquico basado en la "única forma legítima de conocer el mundo: la desplegada por la racionalidad científico-técnica de la modernidad europea" (Castro-Gómez, 2005, p. 47-48). Este pensamiento condenó los conocimientos producidos en las colonias europeas como inferiores para la modernidad. Este fenómeno, denominado colonialidad del poder, hace referencia a la estructura específica de dominación a través de la cual fueron sometidas las poblaciones nativas de América a partir de 1492 (Quijano, 1999). Hoy en día, las nuevas representaciones del desarrollo no significan el final del colonialismo, sino un colonialismo que se materializa de forma postmoderna (Castro-Gómez, 2005; Quijano, 2000).

No se trata de regresar a los saberes del pasado étnico, preservar las culturas, contextualizar los contenidos, ni homogenizar bajo una cortina que disimula la inclusión, sino de construir nuevos criterios de razón, verdad y saber que partan del cuestionamiento y redefinición del actual orden sociocultural (Trapnell, 2009). A partir de lo anterior, la interculturalidad se entenderá desde una mirada crítica de las culturas. Esto porque en el Perú las relaciones culturales se encuentran marcadas por relaciones de poder que traen como consecuencia desigualdad y conflictos entre los diversos grupos culturales y sociales. Esta situación, dentro de un país que se dice democrático, no debería ser aceptable. Con una postura tradicional, pasiva, se corre el riesgo de seguir reproduciendo las condiciones de desigualdad. Por el contrario, una mirada crítica es el punto de partida para comprender la realidad y generar un cambio.

\section{Discursos sobre la Interculturalidad}

En este escenario intervienen diferentes percepciones y visiones de un solo concepto, lo cual evidencia la inexistencia de un marco conceptual compartido sobre la interculturalidad (Walsh, 2002). Por tanto, el concepto es histórico y

3 La transculturación es algo que ocurre entre las culturas hegemónicas y las subalternas e implica integrar lo indígena y popular dentro del marco hegemónico y occidental (Rama 1987; Vich, 2001). 
está determinado por los intereses y la posición social de quienes lo enuncian (Tubino \& Zariquiey, 2005).

Tubino $(2004,2005)$ distingue dos discursos básicos de interculturalidad: el descriptivo y el normativo. Los discursos descriptivos pertenecen al ámbito académico y analizan la interculturalidad desde las relaciones "de hecho" que existen entre culturas. Estos discursos visualizan la realidad como es. Desde esta postura, se tiende a criticar la invisibilización de las relaciones de poder existentes y el dominio entre culturas. Asimismo, analiza el surgimiento de nuevas identidades y formas culturales heterogéneas, así como el derecho al reconocimiento de la diferencia (Zavala, Cuenca \& Córdova, 2005).

Por otro lado, los discursos normativos son propios de dos grupos: las organizaciones indígenas y los educadores. Desde el primer grupo, la interculturalidad tiene que ver con la revalorización de las identidades étnicas ${ }^{4}$. Por su parte, el discurso normativo de los educadores, relacionado directamente con esta investigación, se basa en una concepción de interculturalidad más idealista, donde la interculturalidad implica la actitud de asumir positivamente la situación de diversidad cultural en la que uno se encuentra, muchas veces sin cuestionar las condiciones en las que ésta se da. Esta visión de la utopía intercultural suele ser descontextualizada y abstracta y, al ser aplicada en la escuela, tiende a folclorizarse y banalizarse perdiendo sentido (Tubino, 2004). Por ello, este discurso normativo, propio de la educación, no es capaz de responder a las demandas de los usuarios. De ahí que es necesario articular ambos discursos de la interculturalidad (descriptivo y normativo), ya que estos no son contrapuestos sino más bien complementarios.

Para contribuir a consensuar ambos discursos, Tubino (2004) propone que se asuma un nuevo enfoque de interculturalidad basado en el interculturalismo crítico, diferenciándolo del funcional. Mientras que el segundo promueve el diálogo y la tolerancia, invisibilizando las causas de la asimetría social y cultural hoy vigente, el crítico busca suprimir estas causas por métodos políticos no violentos. Esto es porque la asimetría social y la discriminación cultural hacen

4 En este punto es necesario establecer, en el caso peruano, una diferenciación entre los Andes y la Amazonía, debido a su diferencia histórica. La identidad en la Amazonía se relaciona con lo étnico, lo lingüístico y lo territorial. En los Andes, las organizaciones indígenas se ven más bien amenazadas por lo étnico y articulan su identidad en torno a su lengua, sus actividades agropecuarias y manifestaciones folclóricas. En lugar de afirmarse en la diferencia, muchos actores andinos lo hacen en la inclusión: la lucha no es para exigir respeto a las diferencias culturales sino en contra de las prácticas que siempre los han excluido (Zavala, Cuenca \& Córdova, 2005). 
inviable el diálogo intercultural auténtico. "No hay, por ello, que empezar por el diálogo, sino con la pregunta por las condiciones del diálogo" (Fornet, 2000, citado en Tubino, 2004, p. 3).

Por tanto, en el interculturalismo funcional la interculturalidad es funcional al Estado nacional y al sistema socioeconómico actual, pues no cuestiona el sistema post-colonial vigente y facilita su reproducción, centrándose básicamente en un discurso normativo de la interculturalidad. El interculturalismo crítico exige que se reflexione sobre la realidad para plantear un proyecto ético-político de transformación sustantiva, en democracia, siendo conscientes de las causas que originan las inequidades económicas y culturales. Por ello, busca modificar los procesos que originan las injusticias y desigualdades, no los efectos o los resultados finales.

A partir de lo anterior, se considera que el interculturalismo crítico es el más acertado para empezar a consensuar el concepto de interculturalidad, puesto que concilia el discurso descriptivo y normativo ${ }^{5}$ que manejan los diferentes grupos con sus particularidades. Además, en un sistema democrático, como el que proclama el gobierno peruano, no se puede aceptar que una realidad basada en la exclusión y desigualdad cultural se reproduzca oculta bajo un interculturalismo funcional. Si como peruanos se opta por practicar el interculturalismo crítico y construir las políticas educativas desde esta mirada, se podrá abordar la diversidad identificando por qué se da el conflicto y la dominación y proponiendo alternativas reales (propuesta ético-política) que permitan paulatinamente acabar con las desigualdades existentes.

\section{Análisis de los Resultados}

Este apartado se centra en el análisis de los resultados, lo que incluye los discursos encontrados tanto en las entrevistas a los actores educativos, como en los documentos de política oficiales internos y externos al MED. A través de estos resultados se realiza una reflexión en torno a los principales hallazgos y en cómo las diferentes formas de interpretar y asumir la EIB pueden ser contrarias a los objetivos declarados en las políticas, y sin embargo ser

5 Plantea partir de una reflexión de la realidad (discurso descriptivo), para luego plantear un proyecto ético-político de transformación sustantiva (discurso normativo), en democracia, frente a las inequidades económicas y culturales. 
consistentes con un discurso y enfoque específico (normativo y funcional). Es decir, de qué forma la predominancia de un discurso normativo y funcional a los intereses del Estado, tanto en los documentos de política como en el discurso de los mismos actores, sin venir acompañada de un interculturalismo crítico, puede afectar el objetivo de las políticas educativas interculturales: visibilizar los conflictos de control sociocultural y no ocultar las diferencias y desigualdades, sino trabajar e intervenir en ellas para generar mejoras significativas (Walsh, 2000).

Los principales hallazgos encontrados en el discurso de los actores educativos, según las entrevistas, son los siguientes.

\section{La Predominancia del Discurso Normativo de la Interculturalidad en la Educación Inserto en un Interculturalismo Funcional al Orden Hegemónico}

El discurso normativo predomina en el imaginario de todos los actores educativos entrevistados, principalmente de los funcionarios del MED, y apuesta por la convivencia social. En este discurso, la interculturalidad se convierte en el principio ordenador de la vivencia personal en el plano individual y en principio rector de los procesos sociales en el plano axiológico-social (Zúñiga \& Ansión, 1997). El discurso normativo en sí no es problemático, el problema está cuando se utiliza de forma funcional a los intereses hegemónicos, sin estar acompañado de una perspectiva crítica.

En los discursos de los funcionarios entrevistados del MED (externos a la DEIB), así como de algunos funcionarios intermedios, se visualiza claramente la omisión del conflicto y una tendencia muy marcada a justificar la interculturalidad a partir del discurso normativo desde lo funcional:

[La interculturalidad] sirve para lograr una mejor convivencia entre todos como peruanos, convivencia armónica democrática. (Funcionario MED, secundaria).

Como se observa, se alude a lograr una "convivencia armónica democrática", como uno de los objetivos de la interculturalidad. Aunque los propósitos que se le otorgan son positivos, los actores tienden a invisibilizar los conflictos y las relaciones de poder, mirándola desde lo que se espera de ésta, sin mirar la realidad de la cual se debe partir para llegar a la tan deseada convivencia armónica y al diálogo sobre las diferencias. 
La cita anterior es un ejemplo representativo que evidencia que el discurso normativo de los funcionarios públicos se encuentra inserto en un interculturalismo funcional a los intereses de la cultura dominante, el cual, bajo una lógica multicultural, incorpora la diferencia mientras que la neutraliza y la vacía de su significado efectivo (Zizek, 1998). Lo problemático de que el discurso normativo se inserte en un interculturalismo funcional es que contribuye a que la interculturalidad no apunte a crear sociedades más igualitarias, sino a controlar el conflicto social y conservar la estabilidad, para impulsar el modelo capitalista post-colonial (Zizek, 1998).

Por su parte, los funcionarios entrevistados de la DEIB mencionan los conflictos, la densidad histórica, los prejuicios y la ignorancia, pero no enfatizan el reto más grande de la interculturalidad, que no solo es no ocultar las desigualdades, contradicciones y los conflictos de la sociedad, sino trabajar e intervenir en ellos para superarlos (Walsh, 2000).

En ambos casos, los actores no profundizan ni reflexionan sobre la importancia de visibilizar los conflictos y relaciones de dominación, para lograr las relaciones interculturales que plantea el discurso normativo.

\section{La Idea del "Otro" como Destinatario de la Educación Intercultural}

Detrás de este discurso normativo y acrítico de la interculturalidad desde el interculturalismo funcional, se percibe a las prácticas culturales como propias del "otro". Esta idea se encuentra presente en el pensamiento de aquellos entrevistados que son parte de la cultura dominante, quienes generalmente viven en la ciudad y tienen una visión occidental, heredada del periodo colonial, sumamente etnocéntrica. Es importante aclarar que aunque se hable de la cultura del "otro", no se deja de lado el dinamismo o la rigidez que se le otorgan a las culturas".

Según las entrevistas realizadas, aquellos funcionarios del MED y de órganos intermedios que perciben a la cultura de forma dinámica, en constante relación y cambio, no tienden a cuestionar el conflicto que se da en los

6 Esto es porque dentro de la idea del "otro" existen actores que visualizan a las culturas de forma dinámica -en constante relación- (principalmente los funcionarios del MED y en menor medida los funcionarios intermedios) y otros, como los docentes de costa y selva, que perciben a las culturas de forma estática, rígida. 
encuentros culturales. Por tanto, se habla del dinamismo cultural, pero no se menciona ni cuestiona el conflicto que acompaña a estos cambios culturales, favoreciendo el mantenimiento de las relaciones de poder a favor de la cultura dominante.

Por su parte, los docentes de selva entrevistados que pertenecen principalmente al pueblo asháninka, hacen referencia a la interculturalidad y cultura de la siguiente manera:

Bueno, creo que la educación siempre está a mano con la interculturalidad, en que los alumnos no solamente tienen que conocer su cultura y preservar sino también que además las otras culturas que están dentro del país que también tienen que conocer. (Docente bilingüe asháninka).

El discurso de los docentes indígenas se centra en la "preservación" de las culturas. Walsh (2002) afirma que los movimientos indígenas enfatizan el fortalecimiento de lo propio y particular, por lo que la interculturalidad y la educación apuntarían a este fortalecimiento, paso propuesto como necesario para lograr una interrelación más equitativa con otras culturas. De ahí que muchos docentes indígenas visualizan la interculturalidad y las culturas para mantenerlas y conocerlas.

Esto apunta a una noción de cultura estática y rígida en el tiempo y el espacio. Sin embargo, aunque aluden a la preservación cultural, no se manifiestan sobre el cuestionamiento de las relaciones de poder, la asimetría cultural y las desigualdades culturales. En este sentido, los docentes indígenas entrevistados podrían estar contribuyendo a mantener la situación de asimetría social.

Por su parte, los docentes de zonas urbanas en la costa hacen referencia a las culturas de la siguiente manera:

¿El tema de las culturas, de la diversidad cultural, se trabaja en la escuela?

Sí, sí se trabaja. Por ejemplo cuando se hace las regiones, se hace comida de la costa, ellos hacen algunos postres: mazamorras, arroz con leche. De la selva también quieren hacer algunas cosas. (Docente de nivel primaria, 4 to grado, Lima).

Los docentes de la costa, aunque muestran conciencia de la diversidad cultural, la trabajan como un contenido dentro de la escuela, donde se trata a las culturas a través de su folclorización. Degregori (1999) hace alusión a la forma 
de concebir la cultura dentro de la escuela y afirma que el reconocimiento de la diversidad se queda en el nivel folclórico, cuando ésta abarca mucho más que el patrimonio cultural. A partir de lo anterior, Vich (2005, p. 270) aclara que no se trata de "valorar la diversidad cultural como un simple particularismo estético o como pieza de museo". Esta idea coincide con lo expresado por el docente de educación primaria en la cita anterior, al afirmar cómo se aborda el aprendizaje de las culturas en la escuela, aludiendo a las comidas típicas de cada región. Reducir las culturas al folclore las limita a una época determinada y a los aspectos más tradicionales y visibles de éstas, sin tomar en cuenta los cambios e influencias culturales. Esto da una apariencia de reconocimiento cultural, aunque éste sea superficial. Por tanto, ambas formas de mirar a las culturas (dinámica o estática), contribuyen a ocultar los conflictos culturales y a preservar el poder de las prácticas hegemónicas.

Otra forma de concebir a las culturas tiende a identificar a las prácticas culturales como parte del "otro"7. Comúnmente se piensa que la costa es culturalmente más homogénea y la selva más diversa, pues generalmente lo cultural se percibe como lo que difiere de las formas hegemónicas y, por tanto, aquello que se ha construido como "el otro", percibido desde la perspectiva etnocéntrica de la cultura dominante. Esta percepción de cultura se da a partir de observar cómo es que muchos de los mismos entrevistados se excluyen de la educación intercultural, como si ellos mismos no fueran parte de una cultura, como si occidente fuera algo universal, no cultural. Podemos observar cómo abordan este entendimiento de cultura desde esta mirada:

¿Cómo debería ser una educación intercultural para los que viven en la ciudad?

A ellos debería insertarles las costumbres de la región, de los indígenas, porque ellos van pero comen con lo que trabajan ahí, sacan provecho de la zona, entonces deben de identificarse con la región. (Funcionario DRE Madre de Dios).

Una forma de asumir que la cultura es del "otro", es pensar que la EIB solo debe estar dirigida a zonas rurales y a sus habitantes, principalmente pueblos

7 Esta idea de la cultura del "otro" es transversal a la percepción dinámica o estática de las prácticas culturales que puedan tener los actores educativos. Es decir, convive con ambas percepciones de las culturas. 
indígenas, porque lo occidental no es considerado cultura, o por lo menos no de la misma manera. Por ejemplo, cuando el funcionario de Madre de Dios relaciona la educación intercultural en la ciudad con las costumbres de los indígenas: “... debería insertarles las costumbres de la región, de los indígenas...", está afirmando indirectamente que la educación intercultural implica rescatar, aprender "las costumbres indígenas", identificando a los indígenas como "el otro". Esta forma de entender la cultura y la educación intercultural es asumida por todos los actores entrevistados, menos por los docentes EIB.

En el siguiente caso se asume que la cultura es del "otro", porque se afirma que la interculturalidad se debe poner en práctica con las poblaciones migrantes a la ciudad, que tienen diferentes costumbres. ¿Y qué pasa con los oriundos de la ciudad?, ¿ellos no tienen cultura para ser beneficiarios de un enfoque intercultural?

Acá también existe cultura porque migran, por su pronunciación te das cuenta. (Docente de nivel primaria, 6to grado, costa).

Se considera que la cultura es del "otro" porque la interculturalidad debe estar dirigida a pobladores que migran de las zonas rurales a la ciudad, no a todos, sino a los migrantes, "los que tienen cultura", a "los otros". Estas respuestas son dadas justamente por los que viven en la ciudad, principalmente en la costa, no por docentes de la selva. Por ejemplo, el docente de la costa citado, identifica la existencia del "otro", al cual reconoce por la forma de hablar, sin ser consciente que él también forma parte de una cultura castellano-hablante y que del mismo modo cuenta con una forma particular de hablar. Entonces existe un "centro neutral" desde el cual se concibe a las culturas y ese centro neutral se concibe desde la cultura hegemónica.

No se ha identificado ningún caso de docentes indígenas que se perciban dentro de esta tendencia del "otro". Sin embargo, éstos identifican a la educación intercultural como dirigida a su cultura y se aproximan al conocimiento desde la ciencia occidental, cayendo en la misma disyuntiva, aunque sin referirse al "otro", pero siguen sin cuestionar las relaciones de poder existentes.

\section{¿Qué se debe enseñar en una EIB?}

Nuestra cultura, dentro de nuestras costumbres, de nuestros ancestros, nos han enseñado tal vez tradicionalmente, pero no tecnológicamente. 
Por ejemplo en las plantas medicinales, para hacernos nuestras casas, las rocas, qué tipo de pala hay que sacar, tal vez no ha sido un estudio de cómo hacer la casa, cómo lo vas a armar, pero nuestros padres nos enseñaron tradicionalmente. Cómo se cultiva, qué mes se siembra, qué luna es buena para sembrar el maíz, arroz, etc. (Docente de nivel primaria, asháninka).

En este caso, son los mismos docentes indígenas que siguen identificando a la educación intercultural con los mismos indígenas, dejando de lado el hecho de que la interculturalidad nos compete a todos, indígenas y no indígenas. En este sentido, el entrevistado se refiere a los contenidos de la EIB y reafirma la enseñanza de su propia cultura en la escuela haciendo alusión al rescate cultural de saberes tradicionales. Con esto, fortalece la idea que la educación intercultural debe estar dirigida a los indígenas mediante la inclusión de estos conocimientos en la escuela. Asimismo, realiza una diferenciación entre la enseñanza tradicional y la tecnológica. Como se mencionó, este tipo de mentalidad en los docentes indígenas puede ser consecuencia de subjetividades profundamente arraigadas, cuya explicación, dada por el sector académico, alude a los años de colonización, de predominio occidental, subordinación y exclusión de otras culturas autóctonas.

Por otro lado, hay quienes, además de esta visión de la cultura como del "otro", tienden a la desvalorización, que se expresa de diversas formas, por ejemplo, sugiriendo un "mejoramiento cultural" a partir de la aplicación del enfoque intercultural:

Para nosotros y también para todo docente sugerimos que tiene que convivir con la comunidad, si uno enseña en la comunidad tiene que convivir de acuerdo a como ellos viven y llevar a no discriminarle, y apoyarle con los conocimientos que tiene decirle a los padres de familia cómo podemos mejorar, podemos completar la cultura tanto en la escuela como fuera de escuela, con la comunidad, como viven, haciéndolos ver también las nuevas innovaciones que hay. (Funcionario UGEL Chanchamayo, yánesha).

En las entrevistas se puede identificar la idea de desvalorización del "otro". Por ejemplo, en la cita anterior, a pesar de ser un funcionario indígena, se refiere a "completar la cultura tanto en la escuela como fuera de ella", como si la cultura estuviera incompleta y debe completarse con saberes de otra, por no ser suficientes sus propias prácticas y saberes. Algunos entrevistados aluden 40 I directa o indirectamente al "mejoramiento de las culturas" a través de la inter- 
culturalidad, lo cual refuerza la idea de que ésta es para "los otros", quienes deben "mejorar su cultura". Además, al afirmar que la interculturalidad va a "mejorar" las culturas, inconscientemente se le podría estar restando valor a unas prácticas culturales sobre otras. Esta idea hace referencia nuevamente a la creencia de la superioridad de la cultura hegemónica.

Asimismo, existen opiniones de algunos funcionarios, principalmente de la DEIB y algunos del MED, que muestran conciencia de esta desvalorización cultural, de la existencia de culturas con mayor y menor prestigio:

Yo he hecho una investigación, más bien cualitativa, un primer recojo ¿no?, de apreciaciones en 3 UGELs rurales del país, en zonas pobres y me encontré con que la escuela rural es comparada con la urbana, si tú la comparas con la urbana va a salir perdiendo, hay una desvalorización, al revés, en vez de ver cuáles son los conocimientos las capacidades a las cuales tiene que responder la escuela rural. (Funcionario MED, nivel inicial).

Manifiestan ser conscientes de la situación cultural, pues se refieren a la no valoración o a la desvalorización de la cultura rural frente a la urbana, aunque no son enfáticos al respecto ni aluden a mecanismos para hacer frente a esta desvalorización.

Además de estos hallazgos generales a todos los actores, como son la predominancia de un discurso normativo de la educación intercultural dentro de un interculturalismo funcional y de las interpretaciones de culturas ya desarrolladas, se han identificado en las entrevistas ciertos entendimientos de la educación intercultural más específicos según el rol que juegan los actores entrevistados. Estos discursos son los siguientes.

\section{La Educación Intercultural, como un Eje Transversal del Diseño Curricular Nacional (DCN), sirve para Contextualizar el Aprendizaje (Diversificar)}

Esta noción de la educación intercultural ha sido apropiada centralmente por los funcionarios del MED (externos a la DEIB), así como por algunos funcionarios intermedios y docentes, principalmente de la costa.

Cuando los entrevistados hacen referencia a la interculturalidad como un eje transversal del DCN, se refieren a la diversificación como una forma de 
contextualización. Esta contextualización en las entrevistas se suele plantear de forma directa:

La metodología de la EIB, es cuando hablamos de la contextualización, de acuerdo al contexto... (Funcionario MED, nivel primaria)

O en forma de ejemplo, aunque aluden a la misma idea:

Dentro del Diseño Curricular Nacional al momento de diversificar las capacidades se toma en cuenta las actividades de cada la comunidad... por ejemplo si yo desarrollo, por decir conjuntos, tendría que hablar de conjuntos de árboles frutales de la zona, conjuntos de familias de apellidos... Los problemas por ejemplo tendría que trasladarlos a esto de la madera, la castaña, su productividad que ellos desarrollan, sus trabajos. (Funcionario DRE Madre de Dios).

Como se observa, existe una fuerte tendencia por reducir la educación intercultural a la diversificación curricular, al parecer, sinónimo de contextualización de los contenidos. Lo preocupante de esto es que se pierde de vista lo central de la interculturalidad: la interacción cultural, y con ello se dejan de lado los conflictos y relaciones de poder que pueden surgir al momento de hablar de las diversas prácticas culturales. Esto es porque al contextualizar (diversificar), solo se toman en cuenta los saberes y prácticas de aquel contexto cultural en el que se encuentra inserta la escuela, sea éste andino, costeño o amazónico, y no necesariamente se traen al aula otras prácticas culturales diferentes que puedan entrar en interacción.

Asimismo, la forma como se expresan los entrevistados sobre el currículo, evidencia que su visión de éste y de educación es desde los ojos de la cultura dominante.

Los docentes siempre les decimos que a partir del DCN, la unidad que nos da el DCN, tenemos que tratar de ponerlo en práctica a través de tener en cuenta esa diversidad cultural, de poderlos orientar y ayudar para unir porque uniendo esfuerzo es cuando la colectividad puede proponer alternativas a los problemas que tiene, porque los aprendizajes finalmente tienen que ser para eso, para sacar a los lugares de la postración donde se encuentran. (Funcionario UGEL Islay). 
En la cita anterior se plantea explícitamente la aceptación incuestionable del DCN, el cual se diversifica para tratar la diversidad cultural, tomando como base un diseño que nace y parte desde el contexto hegemónico, para que puedan salir de lo que es considerado por la cultura dominante como lugares de postración. Es evidente que la idea implícita parte de una visión del mundo, y de ser humano en ese mundo, con formas de saber que son superiores a otras, a las cuales se les ubica en una posición subalterna (Trapnell, 2009). De ahí que la diversificación resulta insuficiente para encarar los retos que plantea el ideal ético-político desde una perspectiva crítica de la interculturalidad (Trapnell, 2009; Tubino, 2004).

Es urgente que se desarrollen nuevas formas de pensar el currículo desde otras miradas culturales, más allá de las mismas estructuras y categorías dominantes y que la EIB no se limite solamente a la diversificación, y menos aún a la contextualización (Trapnell, 2009).

\section{Educación Intercultural para Preservar, Conservar, Rescatar a las Culturas (Minoritarias, de Menor Prestigio, la Cultura del "Otro")}

Otra función que los actores educativos entrevistados le asignan a la educación intercultural es la preservación, conservación y rescate de las culturas consideradas de "los otros" desde la perspectiva hegemónica. En algunos casos ambas funciones de la educación intercultural se combinan, es decir, parten de la contextualización para poder revalorizar, rescatar las culturas ancestrales.

Este discurso es compartido tanto por funcionarios intermedios (DREs y UGELs) como por docentes de costa y selva. Sin embargo, es interesante observar que ninguno de los funcionarios del MED se identifica con este discurso pues su posición se restringe a la diversificación curricular.

[En una EIB trabajaría] su origen, partiendo de sus orígenes, cuáles son los orígenes que tienen, trabajar el tema qué es lo que sus antecesores revaloraban esos temas, eso hay que trabajar. (Funcionario UGEL Islay).

[La EIB es para] desarrollar e incentivar la lengua, conservar lo propio de cada lugar, rescatar a los pueblos. (Docente de nivel primaria, costa).

Como se observa en estas citas, predomina la necesidad de preservar las culturas, sobre todo aspectos históricos, ancestrales, como el origen, la lengua 
y las costumbres. Esta tendencia rescata lo tradicional y se aleja del proceso de cambio por el que pasan las culturas, debido a otras influencias culturales.

En el caso de los entrevistados que pertenecen a un pueblo indígena, esta reivindicación podría representar una respuesta frente al proceso de aculturación y a la exclusión histórica de los indígenas de la Amazonía, procesos que forman parte del colonialismo y del postcolonialismo (Walsh, 2002).

Lo anterior podría ser la explicación por la cual, sobre todo los docentes indígenas, se refieren al mantenimiento y rescate de su propia cultura en sus aspectos más esenciales, sin que esto involucre necesariamente todo lo que implica una cultura, producto de múltiples contactos y determinadas por relaciones de poder. De ahí que dentro de la percepción de educación intercultural, un aspecto principal que los actores entrevistados enfatizan es preservar o rescatar lo folclórico de las culturas.

Si las culturas y las identidades se construyen en relación a un "otro", habría que pensar cómo es esta relación con lo que se considera diferente, sobre todo desde el etnocentrismo hegemónico (Vich, 2005). Es en este sentido, que el análisis de las culturas en las escuelas y la educación intercultural no puede limitarse a conocer y reproducir los aspectos más superficiales de las culturas. Se debe transformar las escuelas en espacios de empoderamiento de los pueblos subalternizados y marginalizados (Walsh, 2002).

\section{Predominancia de lo Bilingüe sobre lo Intercultural}

Hay casos en los que la EIB es interpretada como educación bilingüe. Esto podría tener sus raíces en su propia historia, puesto que en un principio solo se hablaba de educación bilingüe y luego se insertó el enfoque intercultural, aunque en la práctica se siguió priorizando lo bilingüe sobre lo intercultural (Zúñiga \& Gálvez, 2005). Esta interpretación es común en todos los actores entrevistados (con excepción de los funcionarios de la DEIB).

\section{¿A qué crees que se pueda referir la EIB?}

A lenguajes, a idiomas, intercambio de idiomas. (Docente de nivel inicial, costa).

Como se observa, la EIB es generalmente asociada con la educación bilin44 I güe, mientras que el componente intercultural pasa a un segundo plano. En los 
entrevistados, autoridades o docentes de la selva, la EIB es importante principalmente para comunicarse y preservar la lengua materna y luego aprender el castellano como segunda lengua:

Respetar su lengua por lo menos que termine la primaria y no pierda su idioma y luego aprenda el lenguaje del castellano. (Funcionario San Martín).

Sin embargo, en la costa simplemente la EIB se identifica con zonas donde no se habla el castellano, restringiendo esta educación a aquellas culturas consideradas de "menor prestigio social".

La educación intercultural bilingüe debería apuntar al estudio de las lenguas de los educandos para fortalecer y valorar las propias prácticas culturales, lo cual va más allá de que las lenguas maternas sean un vehículo para el aprendizaje del castellano. Sin embargo, el hecho de priorizar lo bilingüe sobre lo intercultural dentro de una EIB, podría estar contribuyendo a que se privilegie el uso de la lengua materna para lograr la castellanización, dejando de lado la importancia de las lenguas como medio de prestigio y aprendizaje cultural. Esto llevaría indirectamente a la homogenización cultural, ya que al trabajar la lengua materna en la escuela, como un instrumento de castellanización, se mantienen la estabilidad y el orden social, pero se sigue reproduciendo la situación de dominación cultural existente.

Asimismo, la lengua se toma en cuenta como medio de contextualización y de preservación de la identidad, por lo que es considerada como un elemento fundamental de la EIB y complementaria a los discursos de la educación intercultural anteriormente mencionados.

Retomando los discursos en torno a la ElB, se observa que la interculturalidad podría estar siendo percibida para homogenizar de forma menos violenta o menos traumática. Es decir, la ElB estaría siendo constantemente asociada a las culturas subalternas, consideradas como "el otro", al cual se busca homogenizar, para que se integre a la sociedad hegemónica y mundial. Entonces la convivencia proclamada por el discurso normativo de la interculturalidad, desde un interculturalismo funcional a las prácticas hegemónicas, finalmente llevaría a la homogenización cultural manteniendo la estabilidad social en dicho proceso, para no generar conflictos.

Esta interpretación está presente en diversas respuestas de las entrevistas realizadas. En algunos casos se afirma directamente: 
No ha habido políticas claras para poder unificar. (Funcionario MED, nivel primaria).

Mientras que en otros se apela a posturas menos extremas:

Dentro de una escuela se debería trabajar ambas, tampoco hay que perder nuestra identidad, eso hay que conservarlo siempre pero tampoco podernos cerrarnos a lo que está pasando, a la globalización también tenemos que abrirnos. (Funcionario UGEL Rioja).

Por tanto, se evidencia que por diferentes caminos y desde distintas miradas, la EIB termina convirtiéndose en una forma de ocultar los conflictos, funcionando como cortina para la asimilación paulatina.

En cuanto a los discursos en torno a la EIB en los documentos de política educativa, el documento general de mayor relevancia analizado fue la Constitución Política del Perú de 1993 (Congreso Constituyente Democrático, 1993). Ésta reconoce la pluralidad étnica y cultural del país y contiene algunos artículos referidos al estatus de las lenguas originarias y al fomento de la EIB, aunque de forma dispersa y débil. La Constitución del Perú opera de manera funcional y le otorga una relevancia restringida a la interculturalidad (Dibos, 2005). Por ejemplo, en el caso de las lenguas, la Constitución considera al castellano como idioma oficial y a los demás idiomas nativos solo se les considera oficiales donde predominan. ¿Cómo se pretende acabar con la discriminación, sobre todo lingüística, si los peruanos no nos acercamos por lo menos a las lenguas originarias de la región a la que uno pertenece? Esto también evidencia la existencia de una relación asimétrica entre el castellano y las demás lenguas nativas, ya que se restringe las lenguas aborígenes, sobre todo cuando una lengua oficial requiere de múltiples usos y funciones públicas.

La situación mencionada anteriormente en relación a las lenguas se reproduce con las culturas. Por ejemplo, aunque la Constitución señala que "el Estado [solo] reconoce y protege la pluralidad étnica y cultural de la Nación" (art. 2), no contiene lineamientos que apunten al fomento y enriquecimiento cultural a través de un proceso crítico y dinámico de intercambio y comunicación entre las diferentes tradiciones culturales. Asimismo, la Constitución continúa restringiendo la educación intercultural a las poblaciones indígenas y se limita a utilizar el concepto nominalmente (art. 17), sin aclarar su significado 46 I e implicancias. 
También se han analizado otras normas no educativas pero que mencionan aspectos importantes, como la Ley de Bases de la Descentralización (Congreso de la República del Perú, 2002a), la Ley Marco de Modernización de la Gestión del Estado (LMGE) (Congreso de la República del Perú, 2002b) y el Informe Final de la Comisión de la Verdad y Reconciliación (CVR) (CVR, 2003). Las normativas anteriores aluden a la interculturalidad tímidamente, sin profundizar ni consensuar lo que implica en cada caso. La mayoría solo la mencionan como referente, sin un marco de referencia que contribuya a partir de un concepto común. En estos casos es utilizada principalmente como slogan político dentro de los discursos, vacía de significado. En la LMGE no se menciona nada que haga referencia a interculturalidad, aspecto que Ilama la atención tomando en cuenta que el ideal de interculturalidad tiene que ver con la equidad de poder de decisión y con la democracia participativa, además del empleo eficiente de recursos.

Dentro de los principales documentos de política educativa se analizó la Ley General de Educación (LGE) № 28044 (MED, 2003) y al Proyecto Educativo Nacional al 2021 (PEN) (Consejo Nacional de Educación [CNE], 2007).

La LGE define a la interculturalidad como uno de los principios que rigen la educación en el país (art. 8, inciso f), desde una perspectiva normativa y funcional, un "deber ser" alejado de la realidad, con el riesgo de que se mantenga como un slogan político más. Asimismo, presenta algunas limitaciones que incitan a reflexionar sobre si la EIB es en la práctica beneficiosa. Por ejemplo, además de considerar a la interculturalidad como uno de los principios educativos, la propone en el artículo diez como enfoque para lograr una educación universal, de calidad y con equidad; y en el artículo 20, donde se enuncia que la educación bilingüe intercultural es para todos. No se vuelve a mencionar en el documento, incluso en algunos artículos donde su presencia sería importante. Por ejemplo, en el artículo 9 de la LGE (Fines de la Educación Peruana) no se menciona a la interculturalidad, aunque se menciona que la educación debe "contribuir a formar una sociedad democrática". Esto es contradictorio si se considera que en contextos pluriculturales, como en el caso peruano, las democracias o son interculturales o no son democracias (Tubino, 2004). Asimismo se afirma que la "educación bilingüe intercultural se ofrece a todo el sistema educativo" (art. 20), cuando en los incisos a, b y c de mismo artículo se hace alusión solo a los pueblos indígenas.

Por su parte el PEN (CNE, 2007), incluye a la interculturalidad en sus lineamientos y la define como aquel diálogo para lograr el enriquecimiento 
cultural y el reconocimiento del valor de los productos de diferentes culturas. Asimismo, hace alusión al cambio de la mirada etnocentrista a través de la interculturalidad, a las herencias ancestrales y al fortalecimiento de la identidad cultural como peruanos. A pesar de dichos reconocimientos, esto queda en el discurso político. Además, en el documento la interculturalidad puede ser implícitamente concebida para la educación de los pueblos indígenas, ya que no se aclara lo contrario. En cada uno de los objetivos específicos del PEN se alude a la interculturalidad, en mayor o menor medida, y en algunos casos solo se la menciona a nivel discursivo.

Asimismo, se revisaron documentos más específicos de políticas de ElB como la Política Nacional de Lenguas y Culturas en la Educación (Dirección Nacional de Educación Bilingüe Intercultural [DINEBI], 2002) y la Ley para la Educación Bilingüe Intercultural (LEBI) (Congreso de la República del Perú, 2002c).

En líneas generales se podría afirmar que la Política Nacional de Lenguas y Culturas sigue apostando por el interculturalismo funcional, acrítico, invisibilizando las relaciones de poder y dominación existentes. También se puede notar que en la política hacen falta definiciones pedagógicas, tomando en cuenta la complejidad del carácter sociolingüístico peruano. Este es un aspecto que debe ser considerado dentro de las políticas EIB, debido a que hasta el momento los programas educativos siguen siendo diseñados para niños y niñas monolingües de lengua indígena, que deben aprender castellano como segunda lengua, sin tomar en cuenta los diferentes niveles de manejo del castellano. Tampoco toma en cuenta los criterios de inclusión de las lenguas indígenas en los materiales educativos ni para la implementación de una escuela EIB.

La LEBI "tiene por objetivo reconocer la diversidad cultural y fomentar la EBI en las regiones donde habitan los pueblos indígenas" (Robles, 2007, p. 132). Esto se contradice nuevamente con la LGE, donde se enuncia que la educación bilingüe intercultural debe ser para todo el sistema educativo. Asimismo, en la LEBI se agrega que "el MED diseñará el Plan Nacional de EBI para todos los niveles y modalidades de la educación nacional, con la participación efectiva de los pueblos indígenas en la definición de estrategias metodológicas y educativas, en lo que les corresponda" (Robles, 2007, p. 132). Esta Ley estaría manteniendo y reproduciendo la dominación cultural, ya que sigue planteando que la elaboración de los planes y propuestas de EIB se realice desde el MED, y por tanto desde la visión del Estado y de la cultura dominante, donde no existe la participación de los principales beneficiarios, cuya definición es imprescindible para diseñar la metodología. ¿De qué sirve dejar en manos de los pueblos 
indígenas la metodología si no intervienen en el diseño del plan? La ElB y los asuntos indígenas siguen siendo aspectos relegados en las políticas nacionales y se los restringe a un solo grupo.

Finalmente, también se tomaron en cuenta otras normativas y reglamentos educativos de gestión internos, como el Reglamento de Educación Básica Regular (MED, 2004a), el Reglamento de Educación Básica Alternativa (EBA) (MED, 2004b), el Reglamento de la Gestión del Sistema Educativo (MED, 2005) y el Reglamento de la Ley de Nombramiento de profesores para su ingreso a la Carrera Pública del Profesorado (MED, 2008).

Dichos reglamentos internos presentan varias limitaciones en relación a la interculturalidad. Por ejemplo, el Reglamento de Educación Básica Regular restringe la EIB a zonas rurales y solo a nivel primario (artículo 72). Esto se contradice con la LGE, lo cual se puede apreciar en muchos documentos normativos al interior del MED, ya que a pesar de los cambios en la LGE, muchos de estos documentos no han sido actualizados a la nueva normativa.

En el Reglamento de Educación Alternativa, no se menciona nada en relación a la EIB, solo en relación a la necesidad de un aprendizaje en una segunda lengua. El Reglamento de Ley para el nombramiento de profesores afirma que los docentes que postulen a escuelas EIB, deben hablar la lengua materna y acreditar capacitación necesaria.

Los constantes cambios de los organismos gubernamentales, los vacíos en las políticas y la falta de concordancia que se encuentra entre las leyes vigentes y los proyectos de ley, afectan directamente el futuro de la EIB en el país. A esto se suma la existencia de una desarticulación y desinformación dentro del MED.

Asimismo, la ElB sigue siendo diseñada para escuelas rurales y polidocentes, sin ofrecer lineamientos ni recomendaciones específicas para docentes de escuelas multigrado, como lo son muchas de las escuelas rurales. Como se ha podido apreciar, las políticas existentes responden a un interculturalismo funcional, acrítico. En ningún caso existe un concepto claro de interculturalidad ni de EIB y menos aún consensuado. La interculturalidad es utilizada como slogan político, vacía de significado. Esto coincide con el discurso general que manejan los actores educativos entrevistados.

Asimismo, en las entrevistas se evidenció un desconocimiento general de las políticas de EIB por parte de la gran mayoría a excepción de los funcionarios de la DEIB. Esto evidencia que no solo existe una preocupante desarticulación y desinformación dentro del MED, sino que esta problemática se reproduce 
en los diferentes niveles de funcionarios intermedios hasta los docentes y en otros entes del Estado.

En el caso de los funcionarios del MED que se encuentran dentro de la Dirección de la EBR, las políticas educativas tienen su máxima expresión en el DCN, siendo ellos los principales defensores de la interculturalidad como base para la diversificación curricular.

A su vez se evidencia una falta de actualización y coherencia normativa, lo que fomenta la desarticulación y desinformación entre los funcionarios de las diferentes direcciones del MED, creando un vacío muy grande, obstaculizando el cumplimiento adecuado de las políticas educativas. Esta idea de EIB como eje transversal del DCN, dirigida a sectores rurales e indígenas, se reproduce y tiende a generalizarse fuera de la EBR.

Por otro lado, los funcionarios de los gobiernos regionales y UGELs, manifiestan que interculturalidad es percibida como un objetivo, sobre todo en las regiones que albergan mayor diversidad cultural en el ámbito rural. De ahí que, como se ha visto en las entrevistas y en la mayoría de los documentos de política analizados, los actores suelen identificar a la educación intercultural como aquella educación dirigida principalmente a poblaciones rurales o a pueblos indígenas. Los funcionarios de la costa tienden a darle menos importancia, debido a que en la costa no tienden a prevalecer las culturas concebidas desde la mirada del "otro". Por su parte, los funcionarios de la selva tienden a priorizar una educación que responda a su realidad, dando más peso a la interculturalidad.

Los docentes de zona rural por lo general no se encuentran familiarizados con el concepto de política educativa y desconocen las políticas de la EIB. Estos docentes tienden a pensar en normas más cercanas a su realidad como políticas, ya sea el reglamento de la UGEL o de su propia escuela.

Los docentes de la costa tampoco se encontraban familiarizados con políticas de EIB. Los docentes centran la práctica de la educación intercultural en la elaboración de estrategias para lograr la adecuación curricular a la propia realidad, sin reflexionar o tener una perspectiva crítica sobre la realidad misma en torno a la diversidad cultural y a las relaciones de poder que se han dado y se dan entre las culturas.

Es necesario que los docentes posean las herramientas necesarias para que sean capaces de mirar la educación desde una perspectiva más macro, sin restarle importancia a la educación en el aula. De esta manera serán capaces de tener una mayor participación en la elaboración de las políticas educativas. 
Este desconocimiento general sobre las políticas educativas en relación a la EIB evidencia desinformación y la ausencia de un concepto consensuado y crítico en los documentos de política.

\section{Conclusiones}

Un discurso predominante y que es común en todos los actores educativos entrevistados es el discurso normativo, utilizado como justificación, sustento, ideal y fin último de la educación intercultural. Este discurso, al no estar acompañado de una perspectiva crítica, se encuentra inserto dentro de un interculturalismo funcional, el cual oculta la injusticia cultural y las relaciones de poder, pues no cuestiona el sistema y facilita su reproducción, al pretender interés en la diversidad aunque no genere cuestionamientos ni cambios estructurales.

Otro hallazgo importante se da en relación a la percepción de los actores en torno a las prácticas culturales dependiendo de su origen sociocultural. Los actores provenientes de contextos culturales hegemónicos tienen la tendencia de partir de un "centro neutral" (cultura hegemónica) desde el cual se concibe a las prácticas culturales, consideradas distintas a la cultura dominante, como parte del "otro". Involuntariamente, los actores pertenecientes a la cultura hegemónica la "desculturalizan", no toman consciencia de que también poseen bagaje cultural. Lo central no es la existencia del "otro", lo preocupante es que, desde los contextos hegemónicos, esta percepción del "otro" está ligada a la desvalorización de las prácticas culturales y a la diversidad cultural percibida como un problema. Según lo analizado, esta situación podría tener como base una forma de pensamiento heredada de la colonia, la cual justificaba y garantizaba el predominio de la racionalidad europea, como única forma de conocer el mundo (Castro-Gómez, 2005). Esta teoría de la colonialidad del poder, podría explicar por qué se privilegia a una cultura sobre otras según los resultados de entrevistas realizadas.

En cuanto a la visión del DCN, a raíz de lo anterior se puede interpretar que la idea de currículo que se encuentra presente en el imaginario de la mayoría de los actores entrevistados se basa en la visión de un "otro" desvalorizado y marginalizado. El currículo, al ser un elemento desde el cual se estructuran los conocimientos que se imparten en la escuela, es percibido como reflejo de las políticas educativas. A partir de las entrevistas realizadas, existe una tendencia generalizada de los entrevistados por privilegiar los conocimientos, valores 
hegemónicos y la educación desde la tradición dominante. Esto es porque en la idea de la educación intercultural como eje transversal del DCN, el concepto de interculturalidad se relaciona directamente con la diversificación del aprendizaje. Esta diversificación se reduce a la contextualización de las estrategias y contenidos, lo que implica basarse en un modelo curricular ya establecido, el cual solo debe ser contextualizado (Trapnell, 2008). De esta manera, muchos de los actores educativos manejan un discurso aparentemente inclusivo, donde el concepto de diversificación curricular funciona para pretender que se están considerando los distintos saberes y prácticas culturales. Además, reducir el entendimiento de la educación intercultural a la diversificación (contextualización) curricular, limita en todo sentido las posibilidades que abre la interculturalidad en el contexto educativo. Esto es porque se deja completamente de lado a los conflictos de poder que se podrían presentar en las relaciones culturales, sobre los cuales se podría reflexionar críticamente dentro del ámbito educativo. Incluso la misma interacción cultural, esencia de la práctica intercultural, es ignorada bajo la figura de la interculturalidad como diversificación curricular. Por ello, las políticas de educación intercultural y bilingüe deberían señalar la necesidad de currículos diferenciados, sin convertirlos en meras adaptaciones o diversificación del DCN.

Así, el currículo estaría contribuyendo a invisibilizar y evitar los conflictos culturales al pretender incluir los saberes y visiones de aquellos considerados diferentes, desde el concepto de diversificación cultural (entendida como contextualización). De ahí que esta visión de los currículos básicos vigentes estaría orientada a fomentar un determinado tipo de pensamiento y modelos de acción que responden a los intereses de la cultura dominante.

En esta línea se sugiere la necesidad de desarrollar e incorporar en el currículo capacidades que permitan establecer relaciones con los miembros de los diferentes contextos culturales, abriendo posibilidades de comprensión y comunicación entre ellas. Así se podrá revertir la idea de la diversidad cultural como un problema.

Otro aspecto que se confirma en el discurso de los actores educativos es el discurso culturalmente preservador protagonizado por algunos funcionarios intermedios y docentes, sobre todo aquellos que pertenecen a un pueblo indígena de la Amazonía. Esta forma de hacer educación, como medio de mantenimiento cultural, se centra en llevar al trabajo del aula los aspectos más característicos y visibles de las culturas. Este parece ser el camino más sencillo para trabajar las culturas en la escuela. En este sentido los docentes 
entrevistados sí estarían yendo en contra de la homogenización en forma de resistencia cultural. Sin embargo, durante las entrevistas éstos se caracterizaban por ser acríticos de la realidad y de las relaciones de poder entre culturas.

Otro resultado que es importante mencionar es que predomina un discurso de educación bilingüe sobre lo intercultural. Es necesario resaltar que el uso de la lengua materna dentro y fuera de la escuela es sumamente importante como medio de comunicación, lo cual fortalece aún más las prácticas culturales. Entonces, si se prioriza lo bilingüe sobre lo intercultural se tiende a dejar de lado el estudio de las lenguas para fortalecer y valorar las prácticas culturales y a privilegiar el uso de la lengua materna como medio para el aprendizaje del castellano.

Los discursos expuestos llevan indirectamente a pensar en la educación intercultural como un medio de homogenización menos violento o menos traumático. Esto es porque la educación intercultural y bilingüe está siendo constantemente asociada a quienes son considerados como "el otro" desde la visión dominante y deben integrarse a las prácticas hegemónicas. Frente a esto, los docentes indígenas entrevistados plantean el mantenimiento cultural, sin incluir una reflexión crítica de la situación de las culturas y relaciones de poder en la escuela. De esta manera tampoco estarían apoyando la generación de un cambio y, aunque no contribuyen directamente en la homogenización, sí estarían cooperando de forma indirecta a ocultar los conflictos, conservando la supuesta armonía entre culturas y estabilidad social, para no generar descontentos. De esta manera, las diferentes visiones de los actores en relación a la interculturalidad alimentan la idea de que la convivencia proclamada por el discurso normativo, desde un interculturalismo funcional, finalmente llevaría a la homogenización cultural manteniendo la estabilidad social en dicho proceso para no generar descontentos.

En cuanto a los documentos de política analizados, muchos reflejan una falta de coherencia al interior y entre estos. Las contradicciones más saltantes están en la LGE, porque esta afirma que la EIB debe ser para todos y en la mayor parte de las políticas, sobre todo en los reglamentos internos, la práctica intercultural se restringe a las zonas rurales, especialmente donde el castellano no es la lengua materna. Esto genera una desactualización y falta de coherencia normativa, lo cual fomenta a su vez, la desarticulación y desinformación de las políticas, tanto dentro como fuera del MED.

Además, se podría afirmar que todos los documentos de política educativa analizados fomentan el discurso normativo acrítico inserto en un interculturalismo 
funcional, pues la presentan como aquel "deber ser" que se debe alcanzar, sin hacer alusión a las relaciones de poder y dominación existentes. Por ende, la mayor parte de políticas responden a visiones eurocentradas, presentes en todo el sistema educativo del país.

Asimismo, en ninguno de los documentos analizados se aclara o se precisa cómo se debe entender el enfoque intercultural (¿funcional, crítico?). La palabra interculturalidad parece haberse convertido en un slogan político ${ }^{8}$ que se usa recurrentemente, aunque no esté claro qué involucra y se continúa nombrando a la interculturalidad como un discurso políticamente aceptado, pero sin mayor contenido.

Entonces, un primer aspecto es que si bien los discursos y las funciones de la interculturalidad y de la educación intercultural y bilingüe varían según el grupo de actores, sean estos funcionarios del MED, funcionarios intermedios o docentes, lo planteado en los documentos de política educativa coincide con la mirada de la mayor parte de actores entrevistados, sobre todo de los funcionarios públicos. Esta coincidencia no es en torno a un concepto definido de interculturalidad, sino en la forma que tienen los actores educativos y los documentos de política de asumir la interculturalidad desde un discurso normativo y funcional a los intereses hegemónicos. La problemática es entonces que en ambos casos se evidencia la ausencia de un discurso más crítico de la interculturalidad en la educación. Esto da la impresión de que no hay conciencia plena del problema que se quiere combatir: la injusticia cultural. De ahí que es importante reflexionar si la EIB es en la práctica beneficiosa o solo una forma de esconder la exclusión.

Esta coincidencia entre los discursos de los actores y las políticas señala, sin desconocer los avances de las políticas en relación a la ElB, la necesidad de revisar y repensar las políticas educativas. Lo anterior implica reflexionar, dentro y fuera del Estado y la escuela, sobre los conflictos y relaciones de poder existentes entre tradiciones culturales; poner fin a la creencia generalizada de que EIB es solo un modelo educativo especial para poblaciones rurales e indígenas; apoyar y facilitar el empoderamiento de los diversos actores que no son parte de los contextos culturales dominantes; incluir otras miradas culturales sobre la educación y el conocimiento, sobre todo en el currículo; e identificar los lineamientos claves para consensuar el entendimiento de la interculturalidad en las políticas educativas de forma abierta, crítica y flexible. 
Este concepto consensuado sobre interculturalidad debe ser integrado en los diversos reglamentos y políticas internas del MED, para no desvincular a la EIB del resto de la educación del país.

Además, es necesario considerar las investigaciones y aportes académicos ya existentes, así como ampliar la información sobre la situación de las diversas realidades culturales en el Perú.

Todas las sugerencias mencionadas no dejan de tomar en cuenta el complejo proceso que involucra elaborar o reformular las políticas educativas.

Se deben asumir las diferencias como base de las políticas interculturales, lo que no involucra evadir los conflictos sociales ni invisibilizar las relaciones de poder que existen y se reproducen en los encuentros culturales. Por eso, la necesidad de una perspectiva crítica para abordar la diversidad, en la que se reflexione sobre el contacto cultural, dinámico y cambiante, tomando en cuenta también el conflicto y la dominación.

Con esta investigación se espera haber contribuido a esclarecer y orientar el debate que se encuentra presente en la formulación e implementación de las políticas educativas interculturales y bilingües. Desde la perspectiva crítica, este estudio es un aporte importante para visualizar los discursos de los actores en relación a la interculturalidad, discursos que reflejan las relaciones de poder y dominación que se encuentran presentes en la sociedad peruana. Así se espera contribuir a pensar o repensar en propuestas de política consistentes y realistas, que contribuyan a revertir esta situación y generar un cambio. 


\section{Referencias}

Castro-Gómez, S. (2000). La reestructuración de las Ciencias Sociales en América Latina. Bogotá: Universidad Javeriana.

Castro-Gómez, S. (2005). La poscolonialidad explicada a los niños. Popayán: Universidad del Cauca, Instituto Pensar, Universidad Javeriana.

Comisión de la Verdad y Reconciliación. (2003). Informe Final. Lima: CVR.

Congreso Constituyente Democrático. (2003). Constitución Política del Perú de 1993. Recuperado de http://www.tc.gob.pe/constitucion.pdf

Congreso de la República del Perú. (2002a). Ley de Bases de la Descentralización. Recuperado de http://www.pmde.gob.pe/archivos/leyesynormas/ ley_bases_descentralizacion.pdf

Congreso de la República del Perú. (2002b). Ley Marco de la Gestión del Estado. Recuperado de http://www.unap.edu.pe/transparencia/portal/documentos/documento/ley_27658.pdf

Congreso de la República del Perú. (2002c). Ley para la Educación Bilingüe Intercultural. Recuperado de http://www.elperuano.com.pe/PublicacionNLB/normaslegales/wfrmNormasLista.aspx

Consejo Nacional de Educación. (2007). Proyecto Educativo Nacional al 2021. La educación que queremos para el Perú. Lima: CNE, MED.

Degregori, C. I. (1999). Multiculturalidad e Interculturalidad. En Educación y diversidad rural. Seminario Taller, Julio 1998. Lima: MED.

Dibos, A. (2005). Between being and nothingness? Interculturality in Peruvian public policy. An analysis of the concept and the constitutional and executive practice. Lima: Institute of Social Studies.

Dirección Nacional de Educación Bilingüe Intercultural. (2002). Política Nacional de Lenguas y Culturas en la Educación. Lima: MED.

Fuller, N. (2005). Interculturalidad y políticas: desafíos y posibilidades. Lima: Red para el Desarrollo de las Ciencias Sociales en el Perú.

Ministerio de Educación del Perú. (2008). Reglamento de la Ley de Nombramiento de Profesores para su Ingreso a la Carrera Pública del Profesorado. Lima: MED. Recuperado de http://nombramiento2008.googlepages.com/ ApruebanelReglamentodelaLey.doc 
Ministerio de Educación del Perú. (2005). Reglamento de la Gestión del Sistema Educativo. Recuperado de http://www.minedu.gob.pe/normatividad/ decretos/DecSupN009-2005-ED.pdf

Ministerio de Educación del Perú. (2004a). Reglamentación de Educación Básica Regular. Lima: MED. Recuperado de http://www.spsd.org.pe/leyes/ReglamentoEducaBasica.pdf

Ministerio de Educación del Perú. (2004b). Reglamento de Educación Básica Alternativa. Recuperado de http://www.educared.edu.pe/general/legislacion/430/reglamento-de-educacion-basica-alternativa/

Ministerio de Educación del Perú. (2003). Reglamentación de la Ley General de Educación No 28044. Lima: MED. Recuperado de http://www.minedu. gob.pe/normatividad/reglamentos/EducacionCalidadyEquidad.pdf

Quijano, A. (1999). Colonialidad del poder, eurocentrismo y América Latina. Lima: Centro de Investigaciones Sociales.

Quijano, A. (2000). Colonialidad del poder y clasificación social. Journal of World-Systems Research, 11(2), 342-386.

Rama, A. (1987). Transculturación narrativa en América Latina. México: Siglo $\mathrm{XXI}$.

Robles, A. M. (2007). EIB y participación social. Normas legales 1990-2007. Lima: CARE Perú.

Trapnell, L. (2008). ¿Diversificar o interculturalizar el currículo? Seminario Interdisciplinario "Aprendizaje, cultura y desarrollo". Lima: PUCP.

Trapnell, L. (2009). Descolonizar el saber: un reto para la educación intercultural bilingüe. Ayacucho: VII Congreso Nacional de Educación Bilingüe Intercultural.

Trapnell, L. \& Neira, E. (2004). Situación de la Educación Bilingüe Intercultural en el Perú. Lima: Consultoría solicitada por el Banco Mundial y PROEBI-Andes.

Tubino, F. (2004). Interculturalidad para todos ¿un slogan más? En Palestra: portal de asuntos públicos de la PUCP. Recuperado de http://palestra. pucp.edu.pe/index.php?id=98\&num $=1$

Tubino, F. (2005). Del interculturalismo funcional al interculturalismo crítico. Recuperado de http://www.pucp.edu.pe/ridei/pdfs/inter_funcional.pdf 
Tubino, F. \& Zariquiey, R. (2005). Las prácticas discursivas sobre la interculturalidad en el Perú de hoy. Propuesta de lineamientos para su tratamiento en el sistema educativo peruano. Lima: Consultoría encargada por la Dirección Nacional de EBI.

Vich, V. (2001). Sobre cultura, heterogeneidad, diferencia. En S. López, G. Portocarrero, R. Silva \& V. Vich (Eds.), Estudios culturales. Discursos, poderes, pulsiones (pp. 27-41). Lima: PUCP, Red para el Desarrollo de las Ciencias Sociales.

Vich, V. (2005). Las políticas culturales en debate: lo intercultural, lo subalterno y la perspectiva universalista. En V. Vich (Ed.), El Estado está de vuelta: desigualdad, diversidad y democracia (pp. 265-278). Lima: IEP.

Walsh, C. (2000). Propuesta para el tratamiento de la interculturalidad en la educación. Lima: Consultoría para el MED-UNEBI.

Walsh, C. (2002). (De) Construir la interculturalidad. Consideraciones críticas desde la política, la colonialidad y los movimientos indígenas y negros en el Ecuador. En N. Fuller (Ed.), Interculturalidad y Política (pp. 115-142). Lima: Red para el Desarrollo de las Ciencias Sociales en el Perú.

Zavala, V., Cuenca, R. \& Córdova, G. (2005). Hacia la construcción de un proceso educativo intercultural: elementos para el debate. Lima: MED, DINFOCAD, PROEDUCA-GTZ.

Zizek, S. (1998). Multiculturalismo o la lógica cultural del capitalismo multinacional. En F. Jamerson \& S. Zizek (Eds.), Estudios culturales. Reflexiones sobre el multiculturalismo (pp. 137-188). Buenos Aires: Paidós.

Zúñiga, M. \& Ansión, J. (1997). Interculturalidad y educación en el Perú. Lima: Foro Educativo.

Zúñiga, M. \& Gálvez, M. (2005). Repensando la educación bilingüe intercultural en el Perú: bases para una propuesta política. En N. Fuller (Ed.), Interculturalidad y políticas: desafíos y posibilidades (pp. 309-329). Lima: Red para el Desarrollo de las Ciencias Sociales en el Perú. 